\title{
Draken ömsar skinn: revolution, krig och nationsbygge i Vietnam under 1800- och 1900-talen
}

\author{
Av Hans Hägerdal
}

\author{
Länk till presentation av Hans Hägerdal
}

För att vara ett förhållandevis litet land beläget i det avlägsna Sydöstasien har Vietnam fått häpnadsväckande publicitet i Västvärlden. Filmer, TV-serier och böcker har inpräntat bilden av bitter krigföring i tropisk miljö, på senare år något litet uppblandat med bilden av exotiska turistupplevelser. Alltifrån halvrealistiska skildringar som Plutonen till vulgäropatriotiska amerikanska alster som Rambo ges vi bilden av en segsliten konflikthärd där amerikanerna för en gångs skull inte får fullt ut som de vill.

När man tar del av den typen av filmer delges man nästan alltid intrycket av de vietnamesiska motståndarna som skugglika men fanatiskt stridslystna. De omtalas vanligen med den föraktfulla termen Viet Cong-"vietnamesiska kommunister", eller VC, eller Victor Charlie för att använda de amerikanska soldaternas språkbruk. Längre än så sträcker sig knappast filmernas analys. Viet Cong tycks finnas till för att amerikanerna ska ha något att skjuta på. Men varför Viet Cong huserar i Sydöstasien på 1960- och 1970-talen, det får vi aldrig veta något om.

Men Vietnamkriget var naturligtvis ett högst vanligt krig med högst reella orsaker. Det långdragna kriget 1960 - 1975 var kulmen på den bittra kamp om landets framtid som fortgått sedan 1800-talet. En modern vietnamesisk nation har egentligen bara existerat sedan Vietnamkriget slutade 1975, men försöken att skapa en sådan nation har varit långdragna, besvärliga och blodiga. Just dessa försök att bygga, konstruera en nation är temat för denna artikel. Hur försökte vietnameserna omvandla ett traditionellt

sydöstasiatiskt samhälle till en modernt utvecklande stat? Och varför behövde dessa försök mynna ut i en av 1900-talets bittraste internationella konflikter? Varför skickades unga amerikanska män ut för att slåss i ett land som de flesta amerikaner några år tidigare knappast kunnat peka ut på kartan?

Utan att bli alltför vidlyftig kan det vara lämpligt att börja denna törnbeströdda historia ungefär 150-200 år tillbaka i tiden. Vid denna tidpunkt var Vietnam ett någorlunda väl sammanhållet kungarike som i stora drag omfattade dagens territorium, även om de exakta gränserna var flytande. Men det var någonting annat än vad vi idag skulle kalla en nation. Riket omfattade minst ett femtiotal etniska grupper, men var uppbyggt kring majoritetsfolket kinh som bodde på de odlingsbara kust- och flodslätterna. För att vara ännu mer exakt var det konstruerat kring den lilla lärda eliten i kinhsamhället, och hölls samman av en konfuciansk, kinesiskt inspirerad kultur. Kulturellt var det ett kluvet land redan på 1800-talet. Det var en del av det vidsträckta område som i brist på bättre kallas Sydöstasien och delade många drag med de andra länderna i regionen. Det byggde således sitt välstånd på arbetsintensiv risodling och var inte speciellt inriktat på handel eller manufaktur. Det bestod väsentligen av byar med hög grad av självstyre.

På samma gång hade landet en internationell touche. Kontakterna med det väldiga kinesiska kejsardömet var viktiga och djupgående. Den kinesiska kulturen satte sedan mer än tusen år djupa spår i länderna i Östasien och i stora delar av Central- och Sydöstasien. Det var absolut ingenting man sökte dölja. Tvärtom, den vietnamesiske kungen hänvisade med förkärlek till Konfucius lära (det som västerlänningarna, men inte kineserna själva, kallar konfucianism), och försökte inplantera konfuciansk etik, filosofi, litteratur och 
administration i sitt tropiska rike. Kina var för de härskande i det gamla Vietnam ett sorts kulturellt smörgåsbord. Man plockade ut de bitar man gillade och försökte förädla dem på vietnamesisk mark, samtidigt som det fanns en viss motvilja mot kineser som sådana, och mot samtidens föga livskraftiga kinesiska samhälle. Kineserna å sin sida betraktade vietnameserna som lite halvciviliserade jämfört med folk i det egna samhället. Man kan anföra den rapport som en kinesisk diplomat avgav då han i slutet av 1600-talet besökte Vietnam:

"De läser en smula böcker, men känner nätt och jämnt skrivtecknen. De är dock intresserade av det övernaturliga. Då de inte har någon lärdomstradition finns där ingen djup bildning. De uppskattar trollkonster och följer inte de bägge mästarnas (Konfucius och Buddhas) läror. Vältalighet håller de dock för en förtjänst. Så kan man känneteckna dem med fyra ord: dumma, misstrogna, förslagna och självgoda."

Citatet säger givetvis mer om den rådande kinesiska kulturchauvinismen än om eventuella vietnamesiska realiteter, och erinrar för övrigt slående om vissa europeiska omdömen om koloniserade folkgrupper i Asien och Afrika på 1800-talet.

Det fanns alltså en sorts dubbelhet i det gamla Vietnam. Å ena sidan betonades att man hade sina egna seder och traditioner och sin egen dynastiska historia; å andra sidan såg man upp till fornärvda kinesiska ideal. Någon nationalism kan man naturligtvis inte tala om på detta tidiga stadium, om man därmed menar en föreställd gemenskap där alla nationens medlemmar - medborgare - tänks ha sina givna rättigheter och skyldigheter. Sådant uppkom först i Västvärlden med det sena 1700-talets revolutioner och kunde vinna spridning genom massutbildning och statlig propaganda. Men bland de bildade i Vietnam fanns en patriotism eller rättare sagt en lojalism mot den vietnamesiske kungen och den högcivilisation han representerade. Det skulle komma att bli en grogrund för nationstänkande i framtiden.

Problemen för de kungar som försökte styra 1800-talets Vietnam var i huvudsak två. För det första fungerade inte de högstämda konfucianska principerna om harmoni och moral speciellt bra i den vietnamesiska verkligheten. Ett ordspråk sade att kungens auktoritet slutade vid stängslet som omgärdade byn. Den imponerande konfucianska byråkratin kunde inte riktigt tränga ner på gräsrotsnivån.

För det andra gjorde de europeiska kolonialmakterna aggressiva framstötar i Sydöstasien under 1800-talets lopp. Kolonialismen var i sig inget nytt fenomen; Sydöstasien hade dragits med en europeisk närvaro sedan början av 1500-talet, men fram till 1800-talet inskränkte sig denna till vissa områden i Ostindiska övärlden. En mer utbredd och samtigt fördjupad kolonalism tog vid efter 1800, på grund av en kombination av Europas teknologiska framsteg, behovet av att kontrollera nya marknader och producenter, och rena prestigeskäl. Fram till början av 1900-talet slukade rovgiriga västerländska makter hela regionen utom Siam (Thailand). Sistnämnda land överlevde därför att fransmännen och britterna tyckte alltför illa om varandra för att låta ena parten få övertaget.

I den del av Sydöstasien som kallas Indokina - Vietnam, Kambodja och Laos - fick dock fransmännen förhållandevis fria händer att verka, och under perioden 1858-1883 ockuperades Vietnam av de galliska intränglingarna. För Frankrike spelade den nationella prestigen en stor roll i beslutet att skapa ett kolonialt imperium. Motståndet mot de vita främlingarna var ofta påfallande andefattigt. Phap, som vietnameserna kallade fransmännen, var i Vietnamesernas ögon förhatliga barbarer, eftersom de inte kände och inte ville lära känna de konfucianska ordningarna. De luktade illa, hade ett dåligt temperament och var ute efter snöd vinning och profit. Med lite bättre organisation och stridsvilja borde det ha gått att kasta främlingarna i havet, men så skedde alltså inte. Istället gjorde de vietnamesiska kungarna eftergifter mot de vita männen, alltunder det att det teknologiska gapet alltmer talade till fransmännens fördel. Kolonialismens tidevarv hade gjort sitt inträde, 1858-1940, en plågsam tid av stora förändringar för det vietnamesiska samhället. 
Det vietnamesiska kungahovet förstod självt att tiden sprang ifrån det. En sorgset resignerad ton kan spåras hos en hovfunktionär som adresserade fransmännen på 1880talet:

"Er civilisation är inte bara motbjudande för vår; vi förstår den inte, ser den inte. Ni krossar oss, ibland utan att veta det. Alla dessa lidanden har tröttat ut oss och försatt oss i

förtvivlan. Vi strävar efter ro. Kanske kommer efter oss en generation som omvänts till era idéer, ivriga att rasera och förändra. Vad oss beträffar är vi åldrade barn av en gammal ras. Vi ber bara att få dö i frid."

Kungarna fick sitta kvar som sorgliga maktlösa symboler; de användes av fransmännen för att söka hålla ordning på den mot de vita intränglingarna motspänstiga befolkningen. Allt eftersom deras auktoritet dalade började kolonialisternas inverkan förändra landet på gott och ont. Kanske ändå mest ont. Talar man med till exempel indonesier idag så har de ibland en illa dold nostalgi för den gamla holländska kolonialtiden. Men i Vietnam torde det vara svårt att uppbringa dylika känslor inför den gamla kolonialmakten - den var för de flesta människor alltför vedervärdig för att låna sig till längtansfyllda tillbakablickar. Det har hävdats att den snabba och brutala erövringen av Vietnam beseglade den franska kolonialismens öde från början; den kunde inte skapa någon legitimitet, vilket bäddade för ett våldsamt slut.

Statistiska data tycks underbygga detta. Det genomsnittliga årliga intaget av huvudfödan ris minskade drastiskt med en tredjedel under 1900-talets första decennier. Trots att fransmännen sökte introducera moderna skolor ökade analfabetismen under perioden. Skattetrycket ökade dramatiskt efter 1900, eftersom kolonin måste betala sig. Alla protester slogs ner med mycket hård hand, och den gamla vietnamesiska eliten såg sig förpassad till andra klassens människor i sitt eget land. Samtidigt är det klart att kolonialtiden var viktig för att skapa förutsättningar för ett modernt samhälle. Vägar, järnvägar, broar, sjukvård, utbildningsväsende och nya byråkratiska metoder infördes, även om det bara kom en mindre del av befolkningen till godo. Ekonomin blev mer mångsidig, med nya grödor och industrier.

Hur skulle en vietnamesisk patriot ställa sig inför denna tvetydiga bild? Runt sekelskiftet 1900 stod det klart att traditionella former för motstånd var lönlösa. Antingen det var fråga om bonderesningar eller uppror som använde kungamakten som symbol så slogs de ner av fransk krigsteknologi utan att verkligen kunna hota de vita främlingarna. Läxan var dyrköpt men till slut gick den hem: man kunde inte längre blicka bakåt mot fornärvda konfucianska ideal. Man måste på ett eller annat sätt möta moderniteten, ta upp utmaningen från Västerlandet och bekämpa fransmännen på deras egna villkor.

De män som i tidigt 1900-tal började fundera i sådana banor var å ena sidan påverkade av det västerländska tänkandet om modernitet och framsteg, men var å andra sidan också rotade i den vietnamesiska traditionen. De reformsinnade intellektuella patrioterna tillhörde för det mesta aristokratiska familjer eller ämbetsmannafamiljer. Deras recept på hur man skulle gå till väga för att föra in landet i moderniteten varierade. Det fanns de som ville slänga ut fransmännen med våld och återskapa ett progressivt kungadöme. Den främste företrädaren för denna strategi var Phan Boi Chau (1867-1940), som var något av en fadersfigur för vietnamesisk anti-kolonialism. Andra insåg att fransmännen inte skulle låta sig avhysas så lätt, och menade att man borde sikta in sig på att modernisera inom ramen för den koloniala staten för att så småningom omvandla sig till en självstyrande republik.

Dessa tidiga modernisatörer var patrioter snarare än nationalister i vedertagen mening. Ett begrepp motsvarande nationalism uppkom egentligen inte förrän på 1920-talet på vietnamesisk mark. Nationalism bygger på en utvecklad ideologi om en nation som en entitet med sina särdrag och en medvetenhet om sina medborgerliga förpliktelser och skyldigheter bland de bredare grupperna i samhället. De tidiga patrioterna var mycket intresserade av att sprida utbildning bland massorna, till exempel via fria skolor, men kunde på detta stadium endast nå en begränsad del av befolkningen. 
Fransmännen såg inte oväntat med misstrogna ögon på vad de patriotiska rörelserna hade för sig. Till rörelsernas försyndelser hörde bland annat att de fördjupade sig i upplysningsfilosofer som Montesquieu och Voltaire. Det som i det galliska hemlandet betraktades som oundgängliga klassiker räknades alltså som farliga och subversiva alster på kolonial mark.

På sätt och vis kan man säga att fransmännen bäddade för sin egen undergång som kolonialmakt genom att slå ner även på fredliga och modesta rörelser. Det gav militanta och oförsonliga strömningar större genomslagskraft, och den strömning som skulle komma att bli ledande i vietnamesisk 1900-talshistoria var naturligtvis kommunismen.

Då man betraktar den kommunistiska rörelsens framgång på vietnamesisk botten ligger det nära till hands att jämföra situationen med Kina och även (Nord-)Korea. I alla tre fallen rörde det sig om bondeekonomier i östra Asien med ett starkt konfucianskt arv som betonade hårt arbete, fasta lagar och vägledning genom en upplyst och specialutbildad elit - precis som kommunisterna själva betonade. Att det konfucianska arvet skulle fått en form av fortsättning i den kommunistiska rörelsen har också på fullt allvar hävdats av en vissa vietnamesiska marxister.

Samtidigt som de historiska parallellerna mellan Vietnam och Kina kan verka slående finns det dock en intressant skillnad: det vietnamesiska kommunistpartiet dirigerades av exilvietnameser fram till andra världskriget och var nära förbundet med det bolsjevikiska Sovjetunionen, under det att kommunismen i Kina snarare växte fram som en massrörelse inifrån. Det fanns också markanta skillnader i ledarstil, mellan den dominante och hänsynslöse Mao Zedong och den försiktige gentleman som skulle stå i bräschen för den vietnamesiska revolutionen.

Denne man, som väl får räknas som det tjugonde seklets enskilt viktigaste vietnames, var naturligtvis Ho Chi Minh (1890-1969), en tunn, asketisk man med filosofskägg, inte helt olik den samtide Gandhi i sin framtoning - men med ett betydligt våldsammare budskap. Det var under hans - och Moskvas - auspicier som Indokinas kommunistparti grundades 1930, vars avläggare styr och ställer i Vietnam den dag som idag är.

Vilka var då grunderna till att kommunistpartiet så småningom kunde bli dominerande på vietnamesisk mark? Det har talats mycket om huruvida Ho Chi Minh i första rummet var kommunist eller nationalist - man finner bägge uppfattningarna bland nutida historiker och statsvetare. I sin ytterst omfångsrika biografi över Ho har den amerikanske historikern William Duiker påtalat att frågan på sätt och vis är fel ställd. Ho Chi Minh (som fram till andra världskriget kallade sig Nguyen Ai Quoc) började egentligen inte alls sin politiska karriär som kommunist. Han verkade utanför Vietnams gränser i decennier, från 1911 till 1941, och drogs till kommunismen först kring 1920, vid en tid då han levde i Frankrike. En huvudanledning till Nguyen Ai Quocs ställningstagande var att vare sig de borgerliga politiska partierna eller socialdemokraterna i Frankrike var märkbart intresserade av att verka för en avkolonisering. Världskommunismen, däremot, var en ideologi som tycktes lova goda chanser - förvisso de bästa chanserna - för att befria Vietnam från kolonialismens ok och ena landet på nytt. Det fanns helt enkelt inget incitament bland det politiska etablissemanget för att ändra den koloniala världsordningen. Däremot fanns ett solidaritetsideal inom den Moskvaledda marxismen som utgjorde en avgjord lockelse för en asiatisk intellektuell.

I vilket fall som helst hade Indokinas kommunistparti inte någon verklig chans att gripa makten före andra världskrigets stormar. Den koloniala världsordningen var alldeles för fast förankrad för att kunna ruckas av en begränsad skara patrioter och kommunister, om aldrig så hängivna. Någon substantiell hjälp var heller aldrig aktuellt för Moskva att tillhandahålla. Sovjettrogna kommunistkadrar i Asien var snarare en resurs som kunde vara bra att ha inför eventuella framtida tillfällen. Rörelsens medlemmar blev också illa åtgångna av den franska säkerhetstjänsten, Sureté, under 1930-talets lopp. Det som gav 
kommunistpartiet chansen att så småningom skapa en verklig massnationalism var en fascinerande blandning av inre och yttre faktorer.

I botten ligger återigen den vietnamesiska traditionen. Det fanns i det traditionella bysamhället en stark känsla för de rätta ordningarna, hierarkiska relationerna och moraliska förhållningsreglerna. När dessa ordningar hotades av nya förhållanden och förändringar, som av kolonialismen och senare japanernas och amerikanernas närvaro, blev resultatet en anti-kolonial eller rentav anti-utländsk inställning som kunde kanaliseras i en gryende nationalism. Detta kom att späs på av modern utbildning som visserligen bara nådde en mindre del av befolkningen, men som gav upphov till nya politiska strömningar som ifrågasatte varför ett land skulle tillåtas exploatera ett annat.

Vietnam vid randen till andra världskriget var därför vad historikern Stein Tønnesson kallat "a nation in waiting" - ett land som hade flera förutsättningar för att kunna bli en verklig nation, men som väntade på en katalysator, en utlösande faktor. En sådan katalysator blev just andra världskriget - paradoxalt nog, eftersom kriget i början inte verkade drabba Franska Indokina (Vietnam, Kambodja och Laos) alls lika hårt som andra delar av Sydöstasien. Sedan fransmännen i Europa kapitulerat för den tyska framryckningen sommaren 1940 förpassades de omgående till japanernas knähundar på asiatisk mark. De stora inledande japanska segrarna mot engelsmän, amerikaner och holländare gjorde hela Sydöstasien till en japansk zon och gav kolonialmakterna en obotlig prestigeknäck. Stora arméer kapitulerade för japanska styrkor som ibland var numerärt underlägsna den europeiske motståndaren.

Under Japans hårda övervälde i Vietnam började den lilla men väl sammanhållna kommuniströrelsen att kasta ut sitt propagandanät i allt vidare cirklar. En ny befrielserörelse; Vietminh, bildades 1941. Det var en paraplyorganisation som visserligen dominerades av kommunister men där man tonade ner den kommunistiska retoriken till lägligare tillfälle. Istället propagerade man för en sorts allt-åt-allaprogram som bönder, borgare och arbetare utan svårigheter kunde ta åt sig. Bönder lovades jord, köpmän lovades bättre utkomstmöjlighet, intellektuella påmindes om sin potential som kulturbyggare, och så vidare. Den allmänna idé Ho Chi Minh hade var att man skulle bekämpa japanerna, motverka fransmännen, och söka hålla sig väl med de övriga allierade, inte minst amerikanerna. USA hamnade ju efter 1941 på samma sida som Sovjetunionen i kriget, och hade liksom Sovjet en anti-kolonial framtoning. Speciellt den amerikanske presidenten Roosevelt var känd för att tycka illa om fransk kolonialism. Ho Chi Minh hade stora förhoppningar om amerikanskt bistånd när väl japanerna var borta från scenen.

Redan i mars 1945 gjorde sig japanerna definitivt av med den franska administrationen i Indokina, som sattes bakom lås och bom eller värre. Men genom att göra så skapade japanerna samtidigt ett vacum. Det visade sig lättare sagt än gjort att få lydiga vietnameser att ersätta de franska herrarna i en hast och därtill under brinnande krig. När så Japan preliminärt kapitulerade för de allierade efter fällningen av de två atombomberna, i augusti 1945, blev vacumet fullständigt. Nu hände saker och ting med våldsam fart. Inom loppet av dagar tog Vietminhrörelsen över makten i de större städerna, och detta utan att behöva använda speciellt mycket våld. De desillusionerade japanerna gjorde ingenting för att hejda flodvågen - en del gick t o m med i Vietminh. Kriget hade upphört så plötsligt att det inte fanns någon riktig handlingsberedskap bland de allierade, som inte kunde nå fram med sina egna styrkor förrän efter ett par veckor.

Den systematiska propaganda som Vietminh spred gjorde sin verkan, samtidigt som Vietminh i sig fortfarande var en väldigt oenhetlig rörelse. Augustirevolutionen, som maktövertagandet kallas, har slentrianmässigt setts som resultatet av en lysande organisering, det logiska utfallet av en lång revolutionär uppbyggnadsfas. I själva verket var det inte så enkelt; det förekom mycket av improvisationer och självsvåldigt handlande under dessa dramatiska augustidagar. Icke desto mindre kvarstår faktum att en häpnadsväckande bred folklig entusiasm hade skapats. Höjdpunkten kom den 2 september, då Ho Chi Minh inför hundratusentals jublande åskådare proklamerade Demokratiska 
republiken Vietnam från högkvarteret i Hanoi.

Här hade kanske historien kunnat sluta, och Vietnam kunde eventuellt ha gått en åtminstone halvstabil utveckling till mötes, ungefär som Malaysia eller Filippinerna som fick självstyre respektive full självständighet strax efter kriget. Kanhända hade den eftertänksamme Ho kunnat profilera sig som en gestalt i stil med Jugoslaviens Tito under efterkrigstiden. Som bekant gick det emellertid inte så. Under tre decennier efter krigsslutet, 1945—75, fördes en intensiv och allt bittrare strid om makten i Vietnam. Det var en strid som slutade ungefär som den börjat, med att en marxistiskt dominerad rörelse tog makten i hela landet - med den skillnaden att rörelsen som tog över 1975 var betydligt mer dogmatisk och oförsonlig än den som vann makten 1945. Man kan säga att denna tragiska 30-årsperiod är historien om ständigt missade tillfällen till politiska lösningar.

Kronologin är väl bekant, och jag ska inte fördjupa mig i konfliktens detaljer här, då syftet med denna artikel endast är att peka på huvudfaktorerna i det vietnamesiska nationsbygget. Några allmänna hållpunkter kan ges:

1945 låter amerikanerna och engelsmännen med berått mod sina franska allierade komma tillbaka till Vietnam, Kambodja och Laos - i ljuset av det kalla krigets uppkomst gäller det att hålla Frankrike under armarna gentemot kommunisterna.

1946 utbryter ett fullskaligt krig mellan Vietminh och fransmännen, det Första Indokinakriget, som 1954 slutar med det monumentala franska nederlaget vid Dien Bien Phu 1954. Stora icke-kommunistiska grupper i landet har dock ingen lust att underordna sig en Vietminh-regim.

Samma år 1954 kommer man på en internationell konferens överens om att tillfälligt dela landet på mitten i väntan på allmänna val som ska innebära återförening. I själva verket blir delningen permanent, mellan en kommunistdominerad norddel och en antikommunistisk syddel stödd av USA.

Från 1959-60 börjar Nordvietnam aktivt stödja en vänsterledd gerilla i Sydvietnam, FNL, vilket eskalerar till en större internationell konflikt, Vietnamkriget, där USA utan större framgång griper in för att stötta högerregimen i Sydvietnam och stoppa kommunismen.

Och den 30 april 1975, för jämnt 30 år sedan, rullar nordvietnamesiska stridsvagnar in i den sydvietnamesiska huvudstaden Saigon och enar hårdhänt landet. Vid det här laget är mycket av landet sönderslaget och miljoner människor har mist livet på ett våldsamt sätt.

Det är en oerhört komplicerad historia som sammanfattas på dessa få rader. Men det sagda väcker oundgängligen en fundamental fråga.Varför kom Vietnam att framstå som ett sådant skräckexempel på dålig konflikthantering? Två saker spelar framför allt in här.

För det första hade visserligen både Vietminh och senare FNL breda nationalistiska program som tonade ner det marxistiska ideologiska språket, men de dominerades trots allt av gamla garvade kommunister som ofta uppträdde mycket dogmatiskt. Det stötte tidigt bort en del viktiga grupper som katoliker och borgerliga nationalister. De var heller inte det enda politiska partiet med ett program för nationell uppbyggnad, även om de förblev det i särklass viktigaste. Allt eftersom våldshandlingarna trappades upp efter 1945 blev också kommunisterna och deras meningsmotståndare alltmer oförsonliga.

För det andra kom internationell politik att gripa in på ett oändligt tragiskt sätt i Vietnam. Amerikanerna offrade, när det kom till kritan, sina anti-koloniala ideal på politikens altare och stöttade upp fransmännen under första Indokinakriget 1946—54. De gjorde så av den enkla anledningen att de befann sig på samma sida i det kalla kriget, som hade börjat sprida sin slagskugga över världen. För att hålla tillbaka (contain) kommunismen var man beredd att stöda nästan vilka regimer som helst. Indokina var inte ekonomiskt livsviktigt för fransmännen vid denna tid - snarast var det en black om foten - men av politiska 
prestigeskäl framhärdade fransmännen i kampen så länge det nu gick. Man tycks ha inbillat sig att det skulle gå att fortsätta som vanligt efter den stora prestigeförlusten under andra världskriget. Vilket det alltså inte gjorde.

Under konfliktens andra fas, Vietnamkriget 1960—75, fanns likaledes en huvudtanke hos amerikanerna att man måste hålla tillbaka världskommunismen även till priset av omfattande krigshandlingar. "It was necessary to destroy the town in order to save it" som en amerikansk militär sade i samband med striderna kring en stad 1968. Vietnam var nog inte livsviktigt för USA:s globala intressen, och det kalla kriget var på 1960-talet inne i ett lite stillsammare skede. Då man väl börjat pumpa in resurser för att backa upp den sydvietnamesiska regimen var det emellertid svårt att backa ur utan att förlora i prestige.

Det mesta gick som bekant på tok i den amerikanska strategin i Vietnam. Höga officerare klagade över att civila politiker gav direktiv som hindrade dem från att föra kriget verkligt effektivt - de slogs med ena handen bakbunden, som de sade. I anslutning till detta uppkom myten om att de unga män som sändes till Vietnam utkämpade ett krig de inte tilläts vinna. Även de amerikanska massmedierna och hemmaopinionen beskylldes för att bestulit USA:s armé på segerns frukter genom en överdrivet negativ inställning till krigsansträngningarna.

Frågan är väl dock om det inte är mer värt mödan att studera den vietnamesiska sidan av saken. Här kan man återvända till det nationsbygge som så framgångsrikt påbörjades under andra världskriget, och Vietnams ställning vid denna tid som en nation i vardande. Även för amerikanska historiker har det långsamt börjat gå upp att augustirevolutionen 1945 skapade ett psykologiskt övertag för revolutionärerna, ett övertag som deras motståndare aldrig lyckades komma tillrätta med. De förutsättningar för en massnationalism som fanns kunde aktiveras på ett slagkraftigt sätt av Vietminhrörelsen och senare FNL, där dogmerna tonades ner och de nationalistiska slagorden skruvades upp. I detta kunde man smidigt bygga vidare på den vietnamesiska traditionen av fientlighet mot de främmande inkräktare som störde den egna kulturella ordningen. Genom en smidig organisation kunde man bygga upp en rörelse som nådde långt ner till gräsrötterna. Under 30 år kunde vanliga vietnameser från alla lager av befolkningen entusiasmeras till att bekriga fransmän, sydvietnamesiska regeringssoldater och amerikaner.

Mycket av allt detta gick de amerikanska beslutsfattarnas näsor förbi - de hade svårt att komma underfund med varför FNL egentligen härdade ut i kampen, och de var alltför sena med att söka reformera den korrupta sydvietnamesiska högerregim de stöttade. De fann sig snart stampa i ett tröstlöst träsk där deras överlägsna eldkraft inte försäkrade dem något avgörande. Då slutligen regimen i söder föll för FNL:are och nordvietnameser i april 1975 inskränkte sig amerikanerna till att resignerat betrakta den scen där deras värsta politiska mardrömmar från de senaste decennierna besannades.

\section{(C)}

Att läsa vidare:

William Duiker, Ho Chi Minh; A Life (Hyperion 2000).

Hans Hägerdal, Vietnams historia (Historiska media 2005).

David Marr, Vietnam 1945; The Quest for Power (University of California Press 1995).

Stein Tønnesson, The Vietnamese Revolution of 1945 (Sage Publications 1991). 